\title{
Interorganizational Policy Studies: Lessons Drawn From Implementation Research
}

\author{
Laurence J. O'Toole, Jr.* \\ University of Georgia
}

* A preliminary version of this article
was written while the author served
as research fellow in the joint program
in public administration, Leiden Uni-
versity and the Erasmus University
Rotterdam, during 1989 . This gener-
ous assistance is gratefully acknowl-
edged, as is the support of Auburn
University for the leave period. An
earlier version of the article was pre-
sented at the National Public Manage-
ment Research Conference at the Max-
well School, Syracuse University,
September 1991 . The empirical research reported in this article was financed in part by the U.S. Department of the Interior, Geological Survey, Reston, Virginia, as authorized by the Water Resources Research Act of 1984 (P.L. 98-242), through the Water Resources Research Institute of Auburn University, Alabama. Contents of this

$J-P A R T, 3(1993): 2: 232-251$

\section{ABSTRACT}

Contingency approaches to organizing suggest that policy objectives are more likely to be achieved if the structures employed for implementation mesh with the policy objectives being sought. Interorganizational arrangements are used increasingly in carrying out public programs, and contingency logic can be used to assess the degree of match between policy objective and interunit structure. Such a perspective would seem to offer an approach of practical significance. Here the contingency logic as applied to interorganizational implementation is reviewed and its assumptions identified. To probe these assumptions, empirical evidence is analyzed from one policy sector which would seem especially promising. The findings suggest that even under highly favorable conditions, a contingency perspective provides only limited help. The research demonstrates the need for additional conceptual clarification and theoretical care in reaching conclusions about the impact of interorganizational structures on policy settings.

Complicated interorganizational arrangements are increasingly important in public management. How governance in the public interest may be possible in structures of high interdependence among public and nonpublic actors is a subject of considerable theoretical and practical significance. This article utilizes ideas developed in the study of interorganizational policy implementation to offer guidance regarding three matters: the agenda for interorganizational analysis; the link between analysis and prescription; and the role of the analyst of interorganizational arrangements. 


\section{Interorganizational Policy Studies}

publication do not necessarily reflect the views and policies of the U.S. Department of the Interior. An earlier version of this argument is contained in O'Toole 1990.
An important perspective found in the literature on organizations and policy implementation proposes that interunit structures be assessed for their degree of match, or mismatch, with policy objectives, and that practical suggestions can follow directly from such a contingency evaluation. This proposal is provocative and implies a great deal about interorganizational analysis. The strategy in the present article is to examine critically one version of this contingency approach as applied to multiunit systems. Special attention is given to a test of the assumptions undergirding this type of analysis. The intent is to suggest a set of issues and conclusions that extends beyond those discussed explicitly by contingency theorists or indeed by most interorganizational analysts.

The argument draws from recently conducted empirical work to raise several general questions. The argument in outline form is that the assumptions of the contingency approach are open to question and that this point carries implications for the development of implementation theory, for the conduct of policy research, and for the role of the policy analyst.

\section{CONTINGENCY AND INTERORGANIZATIONAL STRUCTURES: THE ANALYTIC AGENDA AND RESEARCH STRATEGY}

Contingency approaches to the study of organization aim to relate structural attributes to various features of organizational context (see, for example, Greenwood and Hinnings 1976; Greenwood, Hinnings, and Ranson 1975; Pitt and Smith 1981). Typically, the effort links structural patterns with characteristics of organizational task environments. As Peters observes, these approaches have been particularly weak at prescribing matches between structure and environment (1988, 25; see also Hood 1979; Kaufman and Seidman 1970).

Still, there are reasons to expect contingency theory linking policy characteristics with interorganizational structure-intergovernmental grant patterns, public-private partnerships, interunit contract arrangements, and so forth--to hold promise. Government structure and policy content are plausibly related, according to institutional theorists (Ashford 1977). Thus theoretical justifications for "local presence" or "adaptive" implementation networks are driven by contingency logic as applied to the interorganizational policy context (Porter 1976; Porter and Olson 1976; Berman 1978). Indeed, public choice theory itself is based on the idea that "for each particular problem or governmental task, there will be one 'ideal' decision making 


\section{Interorganizational Policy Studies}

unit whose jurisdiction would be just coextensive with the actual extension of externalities" (Scharpf, Reissert, and Schnabel 1978, 65; see also Ostrom and Ostrom 1971).

Some systematic contingency-based implementation studies have been performed. Hull and Hjern, for instance, suggest how empirical theory about the relationship between multiorganizational systems and policy problems can help to unite prescriptive and positive approaches to policy analysis (Hull with Hjern 1987, 200; Hjern and Hull 1982). And Fritz Scharpf and colleagues have developed ideas for tapping the structurepolicy contingency idea (see Scharpf 1977; 1978; 1986; 1987; 1988; Scharpf, Reissert, and Schnabel 1978). In fact, this perspective as developed by Scharpf and his collaborators has been widely influential in Europe (for instance, Harrison and Tether 1987; Hjern and Hull 1982; Hjern and Porter 1981; Rhodes 1980; Sharpe 1985). The following summary of key elements of the contingency approach relies especially on parts of his argument. Yet Scharpf himself recognizes a number of the difficulties inherent in any simple structure-policy problem match. The critique is aimed, therefore, at sketching the difficulties entailed in the contingency idea per se.

\section{The Contingency Approach: A Brief Summary}

The contingency approach begins with the claim that implementation structures based on joint or shared decision making among formally independent organizational units are typically needed for successful policy execution in modern welfare states. Authoritative command patterns involving single bureaucratic units are deemed increasingly rare. The development of intricate intergovernmental agreements and structures, complex interagency-based programs, and the many implementation patterns associated with "government by proxy" (Kettl 1988) are cited as illustrative of the trend.

What sorts of interorganizational arrangements offer the most promise for dealing successfully with such complicated policy issues? No single pattern is optimal. Policy issues require certain types or degrees of coordination among the relevant actors, and the types of coordination requirements vary systematically with the kind of problem being addressed. Scharpf, Reissert, and Schnabel, for instance, develop a typology of policy problem structures and an associated set of control requirements and control instruments (1976; 1978). 


\section{Interorganizational Policy Studies}

Often the actual structure offers a poor fit with the policy problem. Mismatches may stem from political forces, not merely lack of knowledge. Yet the contingency notion can thus lead to a rather convincing overall argument, as follows:

Since it is possible in principle to match policy problems with interorganizational arrangements for implementation, analysis needs to determine the most appropriate structures for particular policy issues and to compare these results with existing interorganizational patterns. The agenda thereby created is a full one, not only because of the array of policy problems to be addressed but because of the various analytical and methodological advances that are required for such a matching effort. ${ }^{1}$ Nevertheless, these tasks should prove to be especially valuable, because they facilitate a synthesis of empirical theory building and practical advice to policy makers and public managers. Since there is an "objective" answer (Scharpf $1978,350)$ to the question of what interorganizational arrangements match the policy issues at stake, the analyst can conduct research that generates results of direct practical import by highlighting "control deficits" and their causes. In so doing, researchers can assist either in resolving such control deficits (as is implied in Scharpf 1978) or, more pessimistically, in encouraging their recognition as immovable constraints of many joint decision making systems (as is proposed in Scharpf 1977), thereby helping to jettison some of the demands unrealistically placed on government. ${ }^{2}$

${ }^{1}$ With regard to the latter, for instance, Scharpf claims that "we ... need to develop and apply methods for the identification and measurement of differences in the 'goodness of fit,' or congruence, between prescriptive policy networks and empirical networks of interorganizational dependence" (Scharpf 1978, 363).

${ }^{2}$ In Scharpf's formulation, policy instruments are also regarded as vital in generating the appropriate coordination. He emphasizes as well that major structural changes are often impractical, and other policies also overlay extant networks (see Scharpf 1977; 1978). This critique addresses only the elements of the contingency logic, not the broader claims.
It is important to recognize the real contribution made by the contingency perspective, for differing institutional arrangements can have predictably varying effects on policy (Scharpf $1984 ; 1986 ; 1988)$. This approach stands as a major contribution to the theory of managing in multiunit systems. Nevertheless, any assessment of the approach must critically probe the key assumptions on the basis of which the contingency idea is so inventively developed.

\section{Matching Policy and Structure: Assumptions of the Approach}

For this general approach to the conduct of interorganizational policy studies to be successful, first, the policy to be studied must not be one that provokes significant disagreements among the organizational elements that are required to be linked during implementation. Second, there must be a defensible way to determine the "objective" structural requirements of the policy. And third, the structural demands of the policy must be recognizable by the major players in the implementation setting. If these conditions are not met, so that 


\section{Interorganizational Policy Studies}

disagreement is present among the actors about either the desirability of the policy or the appropriate interunit arrangement, identifying a structure-policy match that can induce coordinated action is unlikely.

The argument developed below uses findings from some recently conducted research to probe the empirical plausibility of these notions. It is shown that they are unlikely to be met even in apparently straightforward cases. The implications of this conclusion are then sketched.

\section{A TEST OF THE ASSUMPTIONS}

The subject of infrastructure construction for wastewater treatment is suited for use in a straightforward test of the key assumptions on which the contingency approach is based. This is a field in which the U.S. Environmental Protection Agency (EPA) indicates that more than $\$ 100$ billion of new local government spending will be needed between now and the year 2000 (EPA 1988). This case is a policy management problem especially promising as a candidate for assessing match between structure and problem. The three assumptions listed above are all effectively met in the wastewater treatment infrastructure case--or, at least, they are met here in greater degree than is the case for most policy problems being implemented through interunit arrangements.

First, the overall policy of significant investment in wastewater treatment infrastructure is broadly advocated among all major actors in the implementation setting. Even chambers of commerce and other probusiness groups seek regulatory compliance to provide the optimal setting for new growth. Second, the sector's technical features are well understood, at least in comparison with most issues provoking national attention. Third, until the 1980 s there was virtually no disagreement about the appropriateness of the interorganizational structure established to both develop and regulate the wastewater infrastructure. The implementation setting was stable, well accepted, and effective in raising the rate of compliance among local communities and in increasing the quality of the nation's waters. In fact, the only reason alternative interorganizational structures emerged in recent years is that severe budgetary constraints, when coupled with an ostensibly unrelated policy change in another sector (see below), encouraged new organizations to enter the picture.

Prior to recent developments, therefore, one reasonably could expect to have found an interorganizational arrangement well adapted to the wastewater infrastructure policy problem. 
Whether it really was a good match, and whether it is possible even now to tell, are issues addressed presently. It is necessary first to summarize the policy changes of the 1980s that constituted the perturbation to the system and then to compare briefly the dominant interorganizational structure in this policy field with the structure that was induced in a number of cases through policy and spending modifications.

The EPA's treatment plant construction grants program, the nation's primary policy instrument for dealing with capital financing of wastewater treatment plants, was in place for many years but was trimmed in the 1980 s. Competition for funding among localities increased. In 1987, grants began to be eliminated altogether, in favor of a network of state-administered revolving loan funds. During the period from 1981 to 1986 in particular, an alternative involving privatization was explored by many localities. Federal tax law changes in 1981 and 1982 made capital-intensive privatization-that is, a private firm's assuming ownership and complete responsibility for all phases of infrastructure development and operations--much more feasible than it was earlier. For those who had little hope of a construction grant, the choice seemed to be between privatizing, thus reaping a portion of the tax-saving advantages, and financing the project themselves. The peak ofinterest in capital-intensive privatization now appears to have been relatively short-lived. Further tax-law changes in 1986 severely restricted the federal incentives.

In short, therefore, policy shifts during the 1980 s meant that decision makers in several locales opted for privatization as a strategy for infrastructure development. Simultaneously, decision makers in other cases began to implement their projects through the grant-funded option that had been in place but was being slowly phased out. With each of these choices comes a characteristic interunit structure. Treating the two kinds of interorganizational arrangements for implementation as merely a comparison of "public" versus "private" would be oversimplified and misleading. There are many different forms of privatization. (Even in the field of wastewater treatment, contracting for services is much different than encouraging private companies' ownership of a municipal infrastructure; the latter form is examined here.) And there are certainly many varieties of public implementation structures. The comparison here is between a largely public, intergovernmental, grant-funded multiunit structure, on the one hand, and a public-private arrangement involving no direct federal financial support and substantial formal private control, on the other. 
In either the privatized or the grant-funded option the process of regulating the quality of effluence is exactly the same. The state agency (or, in the case of the twelve states that do not have regulatory authority, the national EPA) issues permits specifying standards. Monitoring is conducted by the state (federal) authorities; self-reporting is performed by local implementors, with some oversight from other levels.

What differs is the structure of the arrangements for creating and running treatment plants. There are reasons to expect these differences to matter for implementation at the phases when plants are designed and built. In grant funding, the national EPA and state environmental agencies are asked to play an additional role that is likely to involve a fundamentally different set of multiorganizational relationships, besides that of direct or indirect pollutant regulator. EPA is the granting agency and as such is asked to oversee almost every detail of design, contracting, and construction. The result can be expected to be continuing involvement by the regulators with several parties to the implementation process. In the privatized case, the source of funds for implementation is different and so is the implementation structure. Here the role of the regulator seems to be replaced by two integrating forces: first, the market, which allows relatively unhampered interaction among the banks, design firms, and builders; second, a more simplified normative environment--since once privatization is chosen as the implementation option, virtually all organizational actors are likely to share a basic set of core values and world views involving speed, efficiency, and the need to maintain profit. The structure of the arrangement provides unmistakable encouragement for rapid resolution of any differences.

\section{IMPLEMENTATION FINDINGS: ON THE COMPLICATIONS INVOLVED IN MATCHING STRUCTURE AND POLICY}

What implementation differences can be observed between these two types of settings? And how can these differences help to illuminate the contingency approach discussed earlier? Other studies have included details about what differences could be expected, and they have also presented empirical findings (O'Toole 1989a; 1989b). These are relevant here only insofar as they shed light on the kind of research strategy appropriate for interorganizational public management. The approach used in the empirical portion is summarized as an appendix to the present article; the next several paragraphs summarize the findings in an abbreviated fashion and sharpen the issue of how these results bear on the agenda for the field. 
The research examined differences between privatized and grant-funded interunit structures regarding both implementation process and output. Six matched sets of localities were selected for especially intensive investigation, and these comparisons were supplemented with additional analysis (see Appendix). Some findings of this comparison are directly relevant to the discussion as developed above.

Participants in the privatized cases as a group reported smoother interactions; furthermore, an unobtrusive indicator of process smoothness-the size and number of "change orders" (orders to change design specifications during construction)-indicated a similar conclusion. The most dramatic and unambiguous process difference was in speed of implementation. All matched privatized cases proceeded much more quickly than their counterpart cases; mean difference in implementation time amounted to 29.4 months for design and construction of infrastructure. On output grounds, all cases performed well over the two-year postconstruction period examined. Monthly measures of regulatory compliance were comparable and virtually complete across all cases (see O'Toole 1989a for a more thorough discussion of the evidence).

The findings are, therefore, that these privatized implementation structures create facilities for cleaning wastewater as well as do the federally involved, grant-funded patterns and do so more quickly than do the grant-funded variants; further, this achievement comes at no sacrifice to clean water output. Some economic models even suggest that this form of capitalintensive privatization costs less than grant funding and is even comparable to the nonprivatized and locally self-financed alternative in its effects on the national treasury (Holcombe 1988). However, a closer look suggests that matters are more complex than this comparison suggests thus far.

\section{Limits of the Contingency Approach}

With regard to the earlier discussion of the assumptions underlying the contingency approach, one obvious conclusion is that it may not be so clear after all just when an interorganizational structure provides an optimal match between structure and problem. Improvements induced in the privatized cases were an epiphenomenon of other policy shifts and were largely unanticipated by the regular actors in the policy networks.

Additional implications follow from a closer look at these implementation settings. The empirical results seem to suggest that in this case a nonhierarchical interorganizational structure 


\section{Interorganizational Policy Studies}

was able to "outperform" an established, centrally orchestrated alternative at least on some important measures. However, the comparison across types of settings considers thus far only one type of output from the interorganizational arrangement: clean water, or compliance with regulatory standards. This goal is widely accepted in the various implementation networks, but it is hardly the only such goal. Connecting this point to some additional findings from the empirical project reveals implications for the contingency perspective.

\section{Multiple Goals, Multiple Impacts of Interorganizational Structure}

Thus far the empirical findings have been described in terms largely consistent with the contingency approach's general admonition to researchers: Examine implementation settings for their degree of structural fit with the objective requisites of the policy. But have empirical and prescriptive goals really been unified here? One can answer in the affirmative only if the goal of clean water is not only an accepted one in the interorganizational setting but is also exclusively accepted in the network. In other words, the contingency argument is crucially reliant on another assumption--that there is one and only one policy goal operative in the network. A closer look at the wastewater example can demonstrate that even in a straightforward case, that is, one with a clear, easily measured, and readily accepted policy goal operating in an interorganizational setting, any effort to consider only this objective in determining the match between structure and policy constitutes an oversimplification.

Additional goals in intergovernmental, interorganizational implementation settings can be conceptualized as fitting into four categories (see O'Toole 1989b): (1) additional goals established at the national level directly connected with the policy and subject to the most detailed investigation (examples in this policy sector are national inducements toward the use of "innovative and alternative" technology for wastewater treatment and the use of performance standards regarding increased long-term technical capacity to run treatment plants); (2) other national mandates that apply broadly to several policy sectors (examples here are affirmative action/equal employment opportunity and the regulation of competition between union and nonunion wage scales); (3) goals of state and local governments (these units have objectives that are as legitimate and legitimated--widely accepted, even at other levels-as those obviously mandated in Washington (two examples in this policy field are the preservation of a realm of local autonomy and the protection of accountability channels at the 
local level); and (4) objectives of other participants in the implementation process. Thus "goal multiplicity" is an ubiquitous part of the interorganizational setting. That this generalization applies even for a straightforward case like infrastructure development for wastewater treatment can be suggested by the examples listed under goal categories 1 through 3 above. (The issue is treated in detail in O'Toole 1989b.)

\section{Findings on Multiple Goals and Multiple Impacts}

In this wastewater treatment infrastructure research, further analysis was undertaken to assess the execution of additional policy goals important for public actors in the networks (see Appendix). The findings are illuminating and complex. The overall conclusion is that the interorganizational structures make a difference. Some additional goals that were examined seem to be compromised during implementation under privatized conditions, but these are not goals coming consistently from one level of government. One or two goals actually may have been enhanced in the privatized arrangement. For still other goals there is reason to withhold judgment, since some subtle consequences are likely to emerge only over the long haul.

In short, the move from grant funding to capital-intensive privatization in this policy field appears to be an unambiguous advance, a Pareto improvement, when examined from the viewpoint of clean water process and output. However, when the comparison is conducted on somewhat different but equally defensible grounds, multiple tradeoffs emerge.

One illustration is the goal of local government autonomy. Virtually all actors in the interorganizational patterns examined for this research claimed to accept, and most to support actively, the objective (or, perhaps, metaobjective)--strongly endorsed by the local governments--of local autonomy, usually interpreted in terms of a municipality's ability to have substantial influence over mainly local affairs. An interesting finding, however, is the extent to which local autonomy can be compromised by the shift to privatized structures, as municipalities become heavily dependent on large private firms via long-term contracts that may apportion risks asymmetrically (see O'Toole 1989b). By pursuing indirectly an increased private-sector role in implementation settings, the national government may have diminished the discretion of such other units of government. 


\section{IMPLICATIONS FOR INTERORGANIZATIONAL POLICY MANAGEMENT}

The findings summarized briefly in the preceding section are rich with implications for the field of interorganizational policy implementation. In this section some of the most significant of these are sketched. The section covers lessons for the conduct of research, for the tasks of empirical analysis and prescription, and for the role of the analyst overall.

\section{Lessons: On the Limits of Matching Structure and Policy in Interorganizational Studies}

The larger contingency agenda for interorganizational analysis is called into question by the findings in the case presented above. There is no denying the significance of the insight that interorganizational patterns do display better or worse fits to policy problems. Yet several complications emerge if one attempts to carry out a straightforward analysis even in the simple case of infrastructure development for wastewater treatment. First, the selection of the optimum "objective" match of structure and policy problem, even when one restricts oneself only to clean water matters, is not unambiguous. A well-accepted structure is shown to have deficiencies when compared with a relatively untested alternative generated almost accidentally from other forces in the policy setting. Second, the structures score differently when evaluated separately for implementation process and output, thus suggesting that the structure-policy problem is more intricate. Third, the analysis of the impact of structure realistically cannot be restricted to a simple, single-criterion measure of policy output, even when this goal is widely accepted and salient. In the present context, if clean water is the "mandate" around which policy implementation patterns are built, so are the encouragement of innovative wastewater treatment technology, the achievement of affirmative action goals, and the mitigation of union-nonunion labor competition also policy goals in no less certain a sense. Structures for interorganizational implementation can indeed be compared; such comparisons must be an important part of the field of interorganizational policy management. But the tradeoffs are likely to be complex. Therefore, the role of the analyst becomes simultaneously more complicated, more appropriately hedged by restrictions, but perhaps more important, as explained below. 


\section{Lessons: On Strategic Behavior and Limits of the Contingency Approach}

In fact, independent of the analysis in the preceding subsection, a strong argument can be sketched to show that simple matches between structure and problem are unlikely to be helpful in practice. The actors in interorganizational structures are not indifferent to the implications of the setting for their own sets of goals. These actors are capable of strategic moves. To the extent that the actors in an interorganizational network are aware of the appropriate kind of interunit structure for implementing a widely shared goal, the chances increase that the actors will attempt to "leverage" the network. The easier the imputation of a match between structure and policy problem, the more reason for actors to add objectives, and thus constraints, and thus multiple criteria, to the arrangement. The attractiveness of this approach easily is demonstrated in empirical terms by noting the emergence of scores of "crosscutting" and "crossover" regulations associated with intergovernmental programs in the United States during the last fifteen years (see, e.g., ACIR 1984).

When additional goals incorporated into the interorganizational setting are acceptable across all or most of the actors--and when, as can be expected typically, the "objective" requirements of these policy objectives do not match the structural requirements of the policy problem that provided the original focus for the coordinative effort--then there can be no technical (structural) fix for the interorganizational design problem. Of course, when contentious goals are a part of the setting, or when several goals are widely accepted but are of unequal salience across the network, the notion of a technical fix is even more chimerical. In short, then, the contingency approach to the conduct of interorganizational policy research seems vulnerable to the weakness of its assumptions, especially the idea of straightforward and prescriptively useful structure-policy matches.

Lessons: On the Conceptual Ambiguity of the Top-Down/Bottom-Up Distinction

The conceptual difficulties facing the interorganizational study of policy are highlighted by the findings described above. If the research shows some positive features of a bottom-up perspective, the findings also tend to question implicit assumptions of the bottom-up credo (meant here in a normative sense; see below). The conclusions about privatized settings creating possibilities for reduced local autonomy highlight this point. The findings here are parallel to some conclusions 
reached by scholars of regulatory agencies in the United States, which can have their dependence on regulated interests increased by the ostensibly "independent" commission structure (for example, Bernstein 1955).

That this is so suggests ambiguity in some basic conceptualizations used by researchers in the field. The ambiguity seems to extend to the very notions of top-down and bottomup approaches. There seem to be several dimensions on which top-down and bottom-up perspectives may be distinguished. At least three such dimensions may be identified here:

1. Empirical theory. That is, which variables do researchers assert are the key ones? Some (top-down analysts) assert the prominence of such elements as policy characteristics and central monitoring processes (e.g., Mazmanian and Sabatier 1989), while others (bottom-uppers) argue that contextual, field, or local forces dominate over central ones during the conversion of policy into action (e.g., Porter 1976; Berman 1978).

2. Method. Which part of the implementation world do researchers choose to examine? The distinction between empirical theory and method developed here draws from Elster's analysis of pluralism (see 1979, 113-14, n. 4). Some studies focus at the "bottom" of the implementation arrangement, while others systematically examine those at the "top." It is possible for both groups to conduct research in this fashion without committing themselves to a set of detailed assertions about the relative importance of variables located at different places in the implementation arrangements (Winter 1990).

3. Normative premise. That is, which part of the interorganizational pattern should be given the most leverage to influence what happens? One view (a bottom-up perspective) argues for maximizing leverage at the street level, while another (top-down) sketches the problems inherent in such an approach and seeks central uniformities and constraints--often out of a desire to achieve liberal democratic legitimacy, or to enhance a certain view of equity, or to benefit certain disadvantaged minorities at the local or regional level by redress from the center.

The melding of these dimensions can lead to difficulties in theoretical and practical understanding. The confusion involved in assuming that loosening hierarchical ties means increasing local discretion, or that advocating nonhierarchical structures constitutes advocacy for the interests of those at the bottom may suggest a naive liberal fallacy: that from absence of overt or authoritative links one can infer "freedom" or maneuverability. A theme emphasized by Scharpf (1988) may 
be in order here as a corrective: Analysts need to be sensitive to influence exercised through the arrangement of structures themselves, not simply to the results of discrete observable interactions.

\section{Lessons: On the Need for Broader Investigation of Structural Possibilities}

Beyond the lessons about conceptual clarity and theoretical precision, the findings summarized above contain implications for the conduct of interorganizational research and for the overall field of policy studies. Researchers need to be wary of stereotyped assumptions regarding the impacts of particular types of interorganizational structures on policy settings. Indeed, researchers in the field may need to broaden their investigations of the structural possibilities. Structures for privatization are one important category of arrangements, but they are far from the only example. The present article builds a case that there is no "one best way" to structure settings, even for easy policy issues. And recognizing the strategic character of organizational moves in interunit cooperative settings implies a need for even more caution in any analytical matching effort.

These conclusions in turn mean that the possibility of an empirical/prescriptive melding of activities and roles for the analyst can occur only by omitting from consideration additional, equally legitimate policy problems in the same settinga debatable proposal. Policy networks and settings can be expected to be alive with conflicting or at least competing structural requirements and the consequent need for policy experts at many levels to assess tradeoffs via a range of political criteria.

\section{Lessons: On the Role of the Analyst}

The analyst, consequently, cannot make the leap from empirical investigation to structural prescription without assuming a rather more important role than anticipated by the contingency perspective. Beyond the choices among policy objectives, additional prescriptive implications flow from the kinds of practical suggestions likely to be made by an analyst of interorganizational implementation. How much can and should the policy network be simplified to assist in goal achievement? This question raises the issue of whether the analyst should reduce complexity--more ominously, rig the game structurally--through "selective activation" of networks, "negative coordination," and so forth (see Scharpf, Reissert, and Schnabel 1978). Indeed, this role of the analyst seems to in- 


\section{Interorganizational Policy Studies}

volve several quite explicitly political tasks. These include helping to arrange the network so as to include or exclude certain points of leverage, helping to select policy instruments for their conflict-reducing potential, and assisting in the identification of processes that might move interunit negotiations toward productive problem solving (see, for example, Scharpf 1988).

All these features of the analyst's possible realm of action are very important; they suggest the outlines of an activist role that is far more encompassing than serving as a conduit for the results of empirical analysis. Instead, they can be seen as moves at the level of constitutional choice (see Kiser and Ostrom 1982): The analyst obliquely structures the rules of the game within which policy choices are developed. The difficulty with some versions of the empirical-prescriptive portrayal of the researcher's role is that the argument conveys the misleading impression that the analyst is operating here under the imperative of social science.

The point can be put simply. Analysts may seek influence at the constitutional level; certainly contingency analysts of implementation settings are correct in inferring that interorganizational policy studies have a uniquely important role to play in deliberations about how to structure policy systems. I myself have argued in favor of the use of analysis to influence the structure and problem-solving capacities of joint decision-making settings (see, for example, Montjoy and O'Toole 1991). However, they and their patrons should be under no illusion that such influence consists merely of the elaboration of empirical findings or the logic involved in matching structure with problem.

A recommendation in favor of privatized structures for infrastructure development, to use the case employed in this article, would carry more than analytical or even policy-related momentum. Such a proposal constitutes a suggestion about how certain kinds of basic choices--for instance, whether to give priority to market forces and economic reasoning--should be made in social and political settings. Uniting a structural analysis directly with prescription means seeking to influence how societies "bind themselves" (see Elster 1979, 37). When the analyst moves at the constitutional rather than merely the analytical or even the policy level, he or she is assuming a fundamentally different role than that implied by discussions of objective requirements. 
This point in turn suggests others. The analytical tasks of deciphering tradeoffs and possibly suggesting to actors an array of choices about how they might structure the game means a more elevated role for the analyst of interorganizational studies. However, correlative with this role comes responsibility and related questions of accountability. This recognition is likely to be obscured if one does not clarify the uniquely influential role the analyst assumes. The correlative issue of the kinds of constraints required for appropriate and responsible advocacy by interorganizational researchers in such contexts has not even begun to be explored.

\section{SUMMARY AND CONCLUSION}

Interorganizational structure indeed seems to affect policy action. In view of this finding, theoretical efforts have been made to develop a contingency approach to interorganizational policy management. Such a perspective would seek to determine the most appropriate interunit structures to correspond with various policy problems, to identify settings where policies confront structural mismatches, and to seek practical action in response. Such an approach to interorganizational analysis would seem to provide both a clear agenda for research in the field and a means of fusing the empirical and prescriptive roles of the analyst.

This approach relies on a set of empirical assumptions. It has been shown that even when a policy is widely supported by the variety of implementation actors involved, when its technical features are well understood, and when agreement has been developed among the various parties involved as to the appropriate kind of interunit structure, a contingency approach provides only limited help. Unplanned or innovative structures, such as certain privatized patterns generated by serendipity, may generate performance improvements. A more important limitation flows from a demonstration that the contingency approach requires not only that the policy goal under investigation be accepted through the network, but that it be the only policy goal in the network. In practice a variety of additional goals--typically including several enunciated from the center--entangle the policy matrix. These additional policies also interact with structure, and the results across the range of policy goals are likely to be complex and uneven. Furthermore, to the extent that policy goals are widely supported among the multiple parties involved, those same participants are likely to behave strategically--complicating the matrix in an effort to acquire leverage. 
The evidence here can be employed to demonstrate a variety of conclusions regarding the agenda for interorganizational analysis, the nature of the link between analysis and prescription, and the posture of the analyst of interorganizational settings. The logic developed here demonstrates the need for additional conceptual clarification and theoretical care in reaching conclusions about the impact of interorganizational structures on policy settings. Examining the apparently straightforward case of infrastructure development shows that the interorganizational analyst, when addressing the policy community, directly engages constitutional-level issues of fundamental importance. Thus a close consideration of the agenda for interorganizational studies generates more questions than answers. The encouraging element follows from the recognition that the questions are important and that answering them will help to solve crucial challenges to contemporary governance.

\section{APPENDIX: APPROACH USED IN THE EMPIRICAL INVESTIGATION}

The empirical research focused on differences between privatized and grant-funded interunit structures regarding both implementation process and output. The unit of analysis was the locality and its new treatment plant implementation structure. Virtually all privatized cases for which there were sufficient data for analysis at the time of the field work were included in the data set for analysis.

Six of these were selected for especially intensive investigation. For instance, each was matched with a comparable publicly funded case. (One pair involved a privatized case and a municipally financed rather than federally subsidized instance and is omitted from the discussion that follows.) Cases were matched by state, approximate time period of implementation, scale of facility, community size and demographics, and water quality problems. State regulators nominated candidate matching cases, but the researcher made the actual selections. Substantial data were gathered from two other privatized cases. Detailed interviews and data gathering-- including interviews via a eighteen-page, semistructured questionnaire--took place at all these sites. Additional information was gathered from the other two privatized cases for which there was operating experience at the time of the empirical research. In the field work, the primary subjects were the local officials with major administrative responsibility for the policy; additional interviews were conducted with a variety of other public and private actors. Information was gathered on numerous matters related to wastewater treatment, especially 


\section{Interorganizational Policy Studies}

implementation processes and outputs. One of the matched pairs involved cases administered via the same local agency; this organization had decided to construct two plants nearly simultaneously, and it consciously sought to compare the processes by arranging for one of these to be handled by the grant-funded mechanism and the other to be privatized.

Further steps were taken in the analysis, including a comparison between privatized cities and other cases where privatization was explicitly considered but rejected. Less detailed comparisons developed from the sampling of EPA data bases. Findings from all types of comparisons were consistent (see O'Toole 1989a). However, the matched case analysis is the focus of the discussion here. It offers the best way of controlling for the many potentially confounding variables. Furthermore, the matching approach (and especially the findings from the matched cases in the single locale) suggest that observed differences were not the result of "creaming" by private firms in select sorts of local conditions. For instance, the finding on speed of implementation held clearly for the locale which itself contained matched cases, and it held in a comparison of privatized cases with a larger sample from EPA data bases $(p=.001)$.

To conduct the additional analysis on multiple goals, from which some findings are described in the body of the article, a small subset of the goals identified by the actors in the implementation setting was investigated to assess the relative effectiveness of the structures. Six additional policy goals--two each in categories 1 through 3 above, all widely recognized as important by virtually all actors in the system--were examined to assess the degree of output achieved across the types of interorganizational patterns (O'Toole 1989b).

\section{REFERENCES}

ACIR (Advisory Commission on Intergovernmental Relations).

1984 Regulatory Federalism: Policy, Process, Impact, and Reform. Washington, D.C.: ACIR, February.

Ashford, Douglas E.

1977 "Political Science and Policy Studies: Towards a Structural Solution." Policy Studies Journal: 5: 570-83.
Berman, Paul.

1978 "The Study of Macro- and Micro-Implementation." Public Policy 26: 2: 157-84.

Bernstein, Marver.

1955 Regulating Business by Independent Commission. Princeton, N.J.: Princeton University Press.
Elster, Jon.

1979 Ulysses and the Sirens: Studies in Rationality and Irrationality. Cambridge: Cambridge University Press.

EPA (U.S. Environmental Protection Agency).

19881988 Needs Survey. Washington, D.C.: Government Printing Office. 


\section{Interorganizational Policy Studies}

Greenwood, Royston, and

Hinnings, Christopher R.

1976 "Contingency Theory and

Public Bureaucracies." Policy and Politics 5: 159-80.

Greenwood, Royston; Hinnings, Christopher; and Ranson, $\mathrm{S}$.

1975 "Contingency Theory and the Organization of Local Authorities, I and II." Public Administration 53: 1-23, 169-90.

Harrison, Larry, and Tether, Philip. 1987 "The Co-Ordination of UK Policy on Alcohol and Tobacco: The Significance of Organisational Networks." Policy and Politics 15: 1: 77-90.

Hjern, Benny, and Hull, Chris.

1982 "Implementation Research as Empirical Constitutionalism." European Journal of Political Research 10:2: 105-15.

Hjern, Benny and Porter, David O.

1981 "Implementation Structures: A New Unit for Administrative Analysis." Organization Studies 2:3:211-37.

Holcombe, Randall.

1988 "Tax Incentives and Privatization." Unpublished manuscript.

Hood, Christopher.

1979 "The Machinery of Government Problem." Studies in Public Policy 28. Glasgow: Centre for the Study of Public Policy, University of Strathclyde.

Hull, Christopher J., with Hjern, Benny.

1987 Helping Small Firms Grow: An Implementation Approach. London: Croom Helm.

Kaufman, Herbert, and Seidman, David.

1970 "The Morphology of Organizations." Administrative Science Quarterly 15: 439-51.
Kettl, Donald F.

1988 Government by Proxy. Washington, D.C.: CQ Press.

Kiser, Larry L., and Ostrom, Elinor.

1982 "The Three Worlds of Action." In Elinor Ostrom, ed. Strategies of Political Inquiry. Beverly Hills, Calif.: Sage, 179222.

Mazmanian, Daniel, and

Sabatier, Paul.

1989 Implementation and Public Policy: With a New Postscript. Latham, Md.: University Press of America.

$\rightarrow$ Montjoy, Robert S., and

ƠToole, Laurence J., Jr.

1991 "Policy Instruments and Politics: Multiple Regression and Intergovernmental Aid." State and Local Government Review 23:2: 51-59.

Ostrom, Vincent, and

Ostrom, Elinor.

1971 "Public Choice: A Different Approach to the Study of Public Administration." Public Administration Review 31:2: 203-16.

Ơ Toole, Laurence J., Jr.

1989a "Alternative Mechanisms for Multiorganizational Implementation: The Case of Wastewater Management." Administration and Society 21: 3: 313-39.

1989b "Goal Multiplicity in the Implementation Setting: Subtle Impacts and the Case of Wastewater Treatment Privatization." Policy Studies Journal 18:1: 1-20.

1990 "Contingentie van beleid en organisatorische arrangementen." In J.A.M. Hufen and A.B. Ringeling, eds. Beleidsnetwerken [Policy Networks]. The Hague: VUGA, 121-35.
Peters, B. Guy.

1988 "The Machinery of Government: Concepts and Issues." In Colin Campbell and B. Guy Peters, eds. Organizing Governance, Governing Organizations. Pittsburgh: University of Pittsburgh Press.

Pitt, Douglas C., and Smith, B. C.

1981 Government Departments: An Organisational Perspective. London: Routledge and Kegan Paul.

Porter, David O.

1976 "Federalism, Revenue Sharing and Local Government." In Charles Jones and Robert Thomas, eds. Public Policy-Making in the Federal System. Beverly Hills, Calif.: Sage, 81-101.

Porter, David O., and Olson, E.A.

1976 "Some Critical Issues in Government Centralization and Decentralization." Public Administration Review 36:1:72-84.

Rhodes, R.A.W.

1980 "Analysing Intergovernmental Relations." European Journal of Political Research 8:3: 289-322.

Scharpf, Fritz W.

1977 "Public Organization and the Waning of the Welfare State: A Research Perspective." European Journal of Political Research 5: 339-62.

1978 "Interorganizational Policy Studies: Issues, Concepts, and Perspectives." In Kenneth Hanf and Scharpf, eds. Interorganizational Policy Making: Limits to Coordination and Central Control. London: Sage, 345-70.

1984 "Economic and Institutional Constraints of Full-Employment Strategies: Sweden, Austria, and Western Germany, 1973-1982." In John H. Goldthorpe, ed. Order and Conflict in Contemporary Capitalism. Oxford: Clarendon Press, 257-90. 


\section{Interorganizational Policy Studies}

Scharpf, Fritz W. (cont'd)

1986 "Policy Failure and Institutional Reform: Why Should Form Follow Function?" International Social Science Journal: 179-91.

1987 "The Political Calculus of Inflation and Unemployment in Western Europe: A Game-Theoretical Interpretation." Manuscript draft. Based on a book length study, Sozialdemokratische Krisenpolitik in Europa. Das "Modell Deutschland" im Vergleich. Frankfurt: Campus.

1988 "The Joint-Decision Trap: Lessons from German Federalism and European Integration." Public Administration 66 (Autumn): 239-78.
Scharpf, Fritz W.; Reissert, Bernd; and Schnabel, Fritz.

1976 Politikoerflechtung: Theorie und Empirie des kooperativen Föderalismus in der Bundesrepublik. Kronberg: Scriptor.

1978 "Policy Effectiveness and Conflict Avoidance in Intergovernmental Policy Formation." In Kenneth Hanf and Fritz W. Scharpf, eds. Interorganizational Policy Making: Limits to Coordination and Central Control. London: Sage, 57-112.
Sharpe, L.J.

1985 "Central Coordination and the Policy Networks." Political Studies 33:3:361-81.

Winter, Soren.

1990 "Integrating Implementation Research." In Dennis Palumbo and Don Calista, eds. Implementation and the Policy Process. Westport, Conn.: Greenwood. 